\title{
Research on Pre-School Education Industry Policy and Development
}

\author{
Jiao Zeng \\ South China Business College, Guangdong University of Foreign Studies, Guangzhou 510545 \\ China
}

Keywords: Pre-school education, policy-oriented, industry analysis.

\begin{abstract}
In China's basic education, pre-school education is particularly important for children's physical and mental health growth. Reasonable development of preschool education industry is conducive to the healthy growth of China's youth. This can cultivate talents for the construction of our country and promote the sustainable development of our society. Therefore, China has begun to pay attention to pre-school education. Government and social investment has increased significantly, and the supply quality and demand of education for preschool education have been on the rise. By analyzing the characteristics of preschool education industry in China, this paper forecasts the development and policy direction of preschool education industry based on the current industrial development trend and past policies.
\end{abstract}

\section{Introduction}

Preschool education is both an educational and public welfare undertakings, it plays an irreplaceable role in promoting overall sound development and completing the school readiness and lifelong development, is the welfare of children is the most important. Since the 18th national congress of the communist party of China (CPC), the pre-school education industry has developed rapidly, with the gross enrollment rate of the pre-school three years reaching $77.4 \%$. However, in general, education is still the "shortcoming" of education in China. First, the overall supply of preschool resources is insufficient, especially the inclusive resources. Second, development is uneven, with large regional and urban-rural disparities, and lagging development in the central and western regions, rural areas, ethnic minority areas and border areas. Third, teachers can't keep up with the team, and preschool teachers are hard to be included in the compilation, low pay, poor team stability and low professional quality. In view of these situations, China has actively carried out pre-school education policy reform. In the following part, the author analyzes the current situation and characteristics of China's preschool education market and the reform direction and trend of China's preschool policy.

\section{Current Status of Preschool Education Industry in China}

\subsection{Capital Investment Increases, But Social Capital Accounts for a Low Proportion.}

China has begun to pay attention to the pre-school education industry, with a significant increase in investment funds. Investment in pre-school education is growing rapidly, but its proportion is still low and there is room for improvement. The central government has strongly supported the development fund for pre-school education. In 2014, the public expenditure of education in the national finance totaled 2642.1 billion-yuan, accounting for $4.15 \%$ of the GDP. In 2014, the national preschool education funding increased from 24.5 billion yuan in 2009 to 204.8 billion yuan, and CAGR (5) increased to 52.9 percent. In November 2015, the Chinese ministry of education issued a "national medium and long-term program for education reform and development of early childhood education project assessment, demanding more steady increase financial input to the early childhood education, early childhood education of our country's governments at accounted for the proportion of the state financial education funds at least to 7\% from 3.5\% in 2013. According to 2014 data, the ratio of education to public expenditure of education increased to 7.8 percent. 


\subsection{The Two-Child Policy is Open and the Social Consumption Capacity is Improved.}

The two-child policy was fully relaxed. In 2013 the official start of the implementation of "separate two children" policy in China, was born in 2014 in China's population of 2014, the birth rate is over 14 years of decline in a row, ushered in the upward inflection point for the first time. Since the implementation of the "comprehensive two-child policy" in 2016, the number of births has reached 17.86 million, the highest number since 2000. The number of births in 2016 increased by 1.31 million over the previous year, with the birth rate reaching 12.95 percent. More than 45 percent of the population is born with two or more children. During the 13th five-year plan period, the effects of the comprehensive two-child policy will be released in a concentrated way. It is estimated that 1.6 to 6 million new births will be born each year, accounting for 8-35\% of the 17 to 20 million births. The comprehensive liberalization of the two-child policy has brought demographic dividend to the development of education.

Parents pay more attention to education before school. 80, 90 after generation gradually become a new generation of parents, they generally high level of education and income levels also had a large improvement, under the condition of economic permission to pay more attention to education of their children. According to data from 0 to 6 years old children family income more than 10000 yuan a month early education product used for the expenses in 300 yuan of above accounted for more than $50 \%$, and the income level of ascension, the higher education investment proportion

\section{Characteristics of China's Preschool Education Industry Market}

\subsection{The Supply of Public Kindergartens is Insufficient.}

Public kindergartens are "difficult to enter" and operate overloaded. At present, China's kindergartens are run by public, private, collective and other departments. The sponsor of public kindergartens is a national institution, and the head of kindergartens shall be appointed by the education bureau. The financial department of the government shall pay the school funds and the salaries of teachers and childcare workers. Public garden better conditions for offering education, teachers of high quality and low charge, common for parents of choice, but the public garden enrolment is limited, charge ratio is low, the parents line registration in advance is the norm, the public kindergarten accept ability is limited, in short supply. According to the relevant management regulations, the kindergarten classes in China are generally divided into small, medium and large classes. A small class is generally less than 25 persons; The middle class needs less than 30 people. The large class is under 35. The overall running scale of kindergartens is generally 6, 9 and 12 classes, with no more than 15 classes in principle. Due to insufficient supply of resources for public kindergartens, the number of class members often exceeds the standard. In 2014, the average number of children in private kindergartens was 153, while that of public kindergartens was 273, far exceeding that of private kindergartens.

Private children education refers to educational institutions that recruit young children to the society and are undertaken by social organizations or individuals other than state institutions, and mainly make use of social capital investment. At present, China supports social institutions with school-running qualifications to invest in the construction of standardized private kindergartens, so as to alleviate the pressure of the state on pre-school education. High-end private kindergartens are also attractive. Private kindergarten also because of its low threshold, flexible management, teaching characteristics in the park, etc. has become the beneficial complementarity of the public kindergarten, private kindergarten differences, rural private kindergartens and urban private kindergartens monthly tuition difference can reach more than ten times. Private kindergarten can be divided into Pratt \&Whitney, economical and high-end, Pratt \&Whitney and economical important supplement of the two types of garden is a public garden, especially in the economic underdeveloped areas, shortage of pre-school education resources; Good in public under the condition of high-end kindergarten education, the fewer public park per shift, compared with wang teacher, can provide children with meticulous care, at the same time provide more teaching services, mainly distributed in the city. 


\subsection{Parents Lead the Consumption of Preschool Education and Choose Diversified Demands of Kindergartens.}

Pre-school education experiencers are separated from consumers. Although the recipients of education are children, the actual paying consumers are parents. Children do not have the judgment to choose kindergartens, and their right to speak is very weak. Therefore, children's education consumption is dominated by their parents. According to the survey, the private kindergartens that parents choose are far away from home than those closest to home, so almost all parents will choose kindergartens. Because the kindergarten education is foundation, hard to quantify, parents usually when choosing kindergartens according to some judging visible information, such as the kindergarten's geographical location, environmental conditions, teachers' quality, brand reputation, and so on. Choose a variety of kindergarten needs, close to home is the first. Location parents tend to be the most primary factor, because the young children should be accompanied by parents, transport, its attend kindergarten need longer within the scope of activities in the home, limiting the parents choose area, according to statistics, children go to school site average no more than $2 \mathrm{~km}$ distance from home, so for parents of children's reading convenience, including kindergarten near home, convenient transportation conditions to become the first choice kindergarten. In addition, price, environment, safety, catering, health, complete medical and health care, teacher quality is all considered. Public kindergartens with good geographical location and poor quality have pushed up the housing price of nearby school districts, making it more difficult to choose kindergartens again. There are obvious regional differences in choosing kindergartens. According to a study of the education of scientific research in Shanghai ", the eastern and western region the significant difference of parents to children's education demand, from the point of average, the western, central to the east, parents rising demand for choose the kindergarten, the western parents choose the cause of the kindergarten is mainly "near home"; In the east and the middle, apart from "being close to home", the east attaches importance to the quality of teachers. The average unit price of customers in the eastern region is double that of the central and western regions, and the average monthly payment by parents is higher. The average monthly fee for private parks is 1,122 yuan to the east, while the central (511 yuan) and western (501 yuan) are relatively close, about half the eastern half.

\subsection{The Increase of Public Affairs Will Promote the Transformation of Private Affairs, and the Future Market Will Be Polarized.}

In 2014, the number of public kindergartens only accounted for $25 \%$ of the total number of kindergartens. Private kindergartens accounted for $68 \%$. In terms of number, the number of public parks in 2014 was 15.75 million, accounting for 39\%. The number of private parks in the park was 21.25 million, accounting for 52 percent. The number of people holding collective and other parks was 3.5 million, accounting for $9 \%$ of the total. For we believe that under the circumstances of national policy guide and consumption upgrade, we expect the kindergarten will supply market to the universality and high-end line polarization, universality and high-end private kindergartens kindergarten will lead the market into a dumbbell shape distribution.

\section{China's pre-school Education Policy Trend}

China's preschool education industry is still facing many difficulties. The main reason for these difficulties is that China's current laws restrict the way for social capital to participate in kindergartens. Secondly, due to insufficient earnings of pre-school education enterprises and the inability to form chain brands, the informatization of pre-school education in China is also insufficient. According to the current characteristics, there are two major trends in China's pre-school education policy reform, namely capitalization and informatization.

\subsection{The State Plans to Amend the Law to Liberalize Private Education Profits.}

2015 national plans to revise the package of education law amendment, the bill for private education important change is that eliminates the set of "education for the purpose of profit-making" regulation, at present our country government to allow for-profit private schools, private schools can choose nonprofit or nonprofit agency. Non-profit organizations can enjoy the same preferential 
policies and subsidies as public schools. Delegate power to schools: non-profit schools are set by provincial governments, and for-profit schools have the right to charge their own fees, regulated by the market. We believe that the key lies in the fact that private education from 97 "may not be profitable to 03" can get reasonable return "(a reasonable return is blurred, implementation does not reach the designated position), by 2015" education law amendment (draft) "package" let go "for profit, this is the biggest since" private education promotion law "promulgated legal breakthrough.

Social capital investment is expected to reach a turning point. For capital markets at present, preschool education in the future market potential is great, it takes time to listed companies directly at the kindergarten and accumulation, and through the direct acquisition and kindergarten education company, can quickly cut into the preschool education industry, to improve the quality of the assets of listed companies and valuation, so has the brand, scale of the early childhood education class mark will be affected by the capital market, the childcare industry mergers and acquisitions will be a trend, in the childcare industry social capital growth will mark a turning point.

\subsection{The three-year Action Plan Promotes Pre-School Education Information Management.}

At present our country preschool education of Internet from Europe and the United States, there is still a gap between developed countries, first of all, from the online education, curriculum development, online preschool education abroad (mainly refers to the United States) has been content to precipitate phase, and gradually turned to screening period. The education model in Europe and America is very different in "teaching" and "learning". One of the problems that education faces in China today is that there is still a "classroom mode" in the teaching mode, and our teaching urgently needs to change from "classroom mode" to "game mode". With 2.0 era of education Informatization, the kindergarten will pay more attention to promote the pre-school education informatization construction, and the use of information technology to develop the teaching of game mode, let the child active integrate kindergarten teaching and life, in the right teaching model to promote emotion, attitude, ability and the development of the knowledge, skills, etc.

At present, China has launched the third pre-school education three-year action plan. All provinces in China have put forward requirements for pre-school education informatization and required all kindergartens to establish pre-school education information management system. Compared with primary schools and other education stages, their Internet access rate is 87 percent, the new media teaching classroom is 80 percent, and China's pre-school education information rate is still low. The maturity of information technology and the demands of digital operation and management of kindergartens have pushed the application field of information to education before school. Shenyang is now fully launched the kindergarten education Informatization, in 2017 is expected to more than $50 \%$ in the whole city public park, all public park will be completed in 2018, the city's basic standard construction, so as to realize the overall ascension of education informatization level in Shenyang.

\section{Conclusion}

At present, the policy reform of preschool education is a topic of great concern in China. From the current supply and demand situation of education, it is urgent to reform the capitalization policy of education industry. At the same time, in order to meet the diversified demands of parents, the informatization reform of preschool education industry is also imperative. From these two points of view, China's preschool education policy reform direction will mainly focus on capitalization and information.

\section{References}

[1]. Several ways to optimize teacher resources in our garden [J]. Ma Xiaohong. Research on education before school.2004(Z1).

[2]. A brief discussion on the current situation and countermeasures of resource allocation of preschool education teachers in rural areas $[\mathrm{J}]$. Weng Yiran. China's collective economy.2018(10). 
[3]. Win in co-building and sharing -- a practical study on co-building and sharing of teacher resources based on children's personalized development [J]. Yao Lijuan. Jiangsu education research.2015(13).

[4]. Analysis on the causes and countermeasures of shortage of education funds for preschool education in western rural areas $[\mathrm{J}]$. Yan Han. Contemporary education BBS (macroscopic education research).2008(11).

[5]. the return and guidance of traditional games for preschool children in rural areas [J]. Meng Qingyan. Journal of Jiamusi vocational college.2015(03).

[6]. the decline of children's folk games in Huaian rural areas and its causes [J]. Zhang Xinli, Qiu Gaogan. Journal of Huaiyin normal university (natural science edition).2010(05).

[7]. thinking on countermeasures of preschool education teacher training in western rural areas [J]. Ju can, wang Fangguo. Reading and writing (education teaching journal).2012(01).

[8]. research on the development and utilization of preschool physical education teacher resources -taking Fuzhou A kindergarten as an example [J]. Liu Dingyu. Journal of Chifeng college (natural science edition).2015(21).

[9]. analysis on the causes and countermeasures of resource loss of preschool teachers [J]. Feng Jiangying, Sun Yuhua. Journal of Xinjiang education college.2007(03).

[10]. development and utilization of rural curriculum resources in rural areas of ethnic minorities [J]. Wang ji. Northern literature (second half of the month).2011(04). 